\title{
Influence of dipping time on cracking during bending of hot dip galvanized coatings with $\mathrm{Sn}$ and Ti contents
}

\author{
V. Di Cocco \\ Università di Cassino, Di.M.S.A.T., via G. Di Biasio, 43 03043, Cassino (FR), Italy \\ v.dicocco@unicas.it \\ L. Zortea \\ Università di Roma "Sapienza", Dip.I.C.M.A., Via Eudossiana 18, Roma, Italy
}

\begin{abstract}
In the last years, the attention to environmental topics led a new approach solution in classical protection techniques, introducing innovative way oriented to optimize different coating properties. Hot-dip galvanizing is a classical process aimed to generate coatings on iron-based surfaces, used unchanged since 200 years: some chemical elements are added in the bath with different aims (e.g., $\mathrm{Pb}$ is really important for its fluidizing properties, sometimes replaced by $\mathrm{Sn}$ ) but sometimes these elements are dangerous for human health (e.g. ... Pb!).

In this work, the influence of dipping time and coatings chemical compositions on damaging micromechanisms was investigated considering different $\mathrm{Sn}$ and Ti contents. Main damaging micromechanisms in hot dip zinc coated ipersandelin steel specimens were investigated by means of bending tests. Longitudinal sections of bended specimens were observed by means of a LOM (Light Optical Microscope): main damage micromechanisms were identified as longitudinal and radial cracks.
\end{abstract}

KEYwORDS. Hot dip galvanizing; Intermetallic phases; Damage analysis.

\section{INTRODUCTION}

$\mathrm{P}$ rinciples of hot dip galvanizing have remained unchanged since this coating came into use over 200 years ago. Actually, it is still one of most important processing technique to protect carbon steels against corrosion in many corrosive environments [1].

In the last decades, new investigations on bath compositions were performed to generate coatings "mechanical behaviour" oriented to use in high plastic deformations [1-4] or in reinforced components.

$\mathrm{Zn}$-based coatings growth is a diffusion driving phenomenon, where $\mathrm{Zn}$ and $\mathrm{Fe}$ atoms are characterized by interdiffusion at high temperature [5]. Many intermetallic phases could be obtained depending on $\mathrm{Zn}$ contents [3]: these phases are characterized by different chemical compositions, morphologies and mechanical behaviour.

Four intermetallic layers are usually observed in classical $\mathrm{Zn}, \mathrm{Zn}-\mathrm{Pb}$ and $\mathrm{Zn}-\mathrm{Sn}$ coatings: they are characterized by different Fe contents (Fig. 1). The inner layer, namely $\Gamma$ phase (generally BCC), is characterized by the highest Fe content $(17-28 \mathrm{wt} \%)$, and by a very low thickness, often negligible [3]. $\delta$ phase is characterized by a Fe content ranging between 7.0 and $11.5 \mathrm{wt} \%$, with HCP unit cell and a brittle behaviour. $\zeta$ phase, located between $\delta$ and the outer phase, is characterized by a radial oriented morphology, due to growth mechanisms. Depending on the hot dipping conditions, it is possible to obtain a $\zeta$ phase with not-oriented morphology [6]. The outer layer ( $\eta$ phase, HCP) is characterized by a ductile behaviour and by a very low Fe content. 
In this work, the influence of dipping time and coatings chemical compositions on damaging micromechanisms was investigated considering different $\mathrm{Sn}$ and Ti contents by means of bending tests and LOM (Light Optical Microscope) observations.

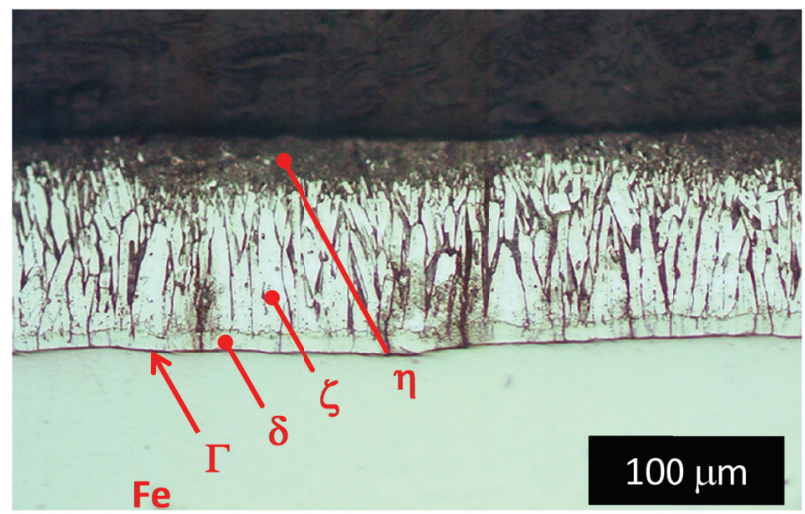

Figure 1: Zn coating section: intermetallic phases.

\section{MATERIAL AND EXPERIMENTAL PROCEDURES}

7 hree different bath compositions were considered: pure $\mathrm{Zn}, \mathrm{Zn}+3 \% \mathrm{wt} \mathrm{Sn}, \mathrm{Zn}+0.5 \% \mathrm{wt}$ Ti. Zinc coatings were performed at $460^{\circ} \mathrm{C} \pm 2{ }^{\circ} \mathrm{C}$, considering five different dipping times: $15,60,180,360$ and $900 \mathrm{~s}$. For all the fifteen coating, $3 \mathrm{~mm}$ thick commercial ipersandelin carbon steel plates were used (Tab. 1).

The following procedure was used for coating the plates. They were degreased and rinsed with alcohol and pickled in an aqueous solution $20 \% \mathrm{H}_{2} \mathrm{SO}_{4}$ at $50^{\circ} \mathrm{C}$ for 10 minutes, washed in fresh water, fluxed in an aqueous solution containing 280 $\mathrm{g} / 1 \mathrm{ZnCl}_{2}$ and $220 \mathrm{~g} / 1 \mathrm{NH}_{4} \mathrm{Cl}$ at environment temperature for 2 minutes and dried for 10 minutes at $100^{\circ} \mathrm{C}$ and then dipped in the zinc bath. All galvanized plates were air cooled.

\begin{tabular}{ccccccc}
\hline $\mathrm{C}$ & $\mathrm{Si}$ & $\mathrm{Mn}$ & $\mathrm{P}$ & $\mathrm{S}$ & $\mathrm{Al}$ & $\mathrm{Fe}$ \\
0.090 & 0.167 & 0.540 & 0.010 & 0.004 & 0.051 & Bal. \\
\hline
\end{tabular}

Table 1: Steel chemical composition (wt \%).

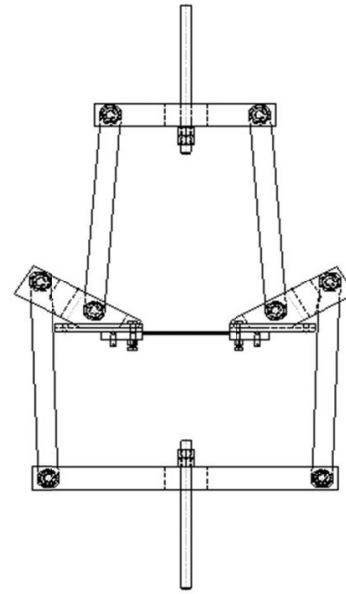

(a)

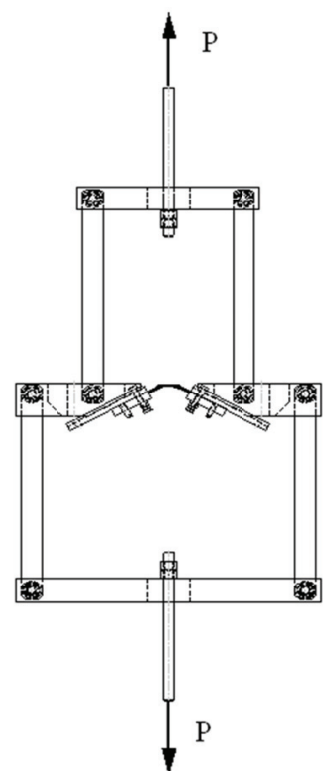

(b)

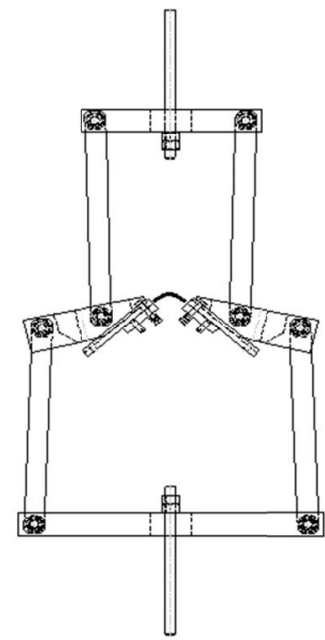

(c)

Figure 2: Different clamping configurations: a) Starting position; b) Pure applied bending moment; c) $30^{\circ}$ position $[8,9]$. 
Microstructure analysis was performed by means of traditional metallographic techniques (LOM observations) and performing scanning electron microscope (SEM) analysis, with EDS. Vickers microhardness tests were also performed $(0.1 \mathrm{~N}-15 \mathrm{~s})$.

Bending tests were performed by means of a non-standard device (Fig. 2a) and repeated at least three times for each investigated condition. An electromechanical $100 \mathrm{kN}$ testing machine was used, considering a crosshead displacement equal to $35 \mathrm{~mm}$, that corresponds to a bending angle equal to $30^{\circ}$ (Fig. 2c) [7-11]. Finally, in order to identify the damaging mechanisms for each investigated loading condition, longitudinal sections of the bended specimens were metallographically prepared and observed by means of a LOM. Damage level was evaluated in term of "cracks density", defined as cracks number/coating length [12-14].

\section{EXPERIMENTAL RESULTS}

\section{Intermetallic phases growth kinetics}

$\mathrm{F}$ ig. 3 shows binary Zn-Fe and Zn-Sn phase diagrams. The first is characterized by the presence of the "classical" intermetallic phases and the second does not show intermetallic phases and is characterized by the presence of an eutectic transformation corresponding to very high Sn contents. Both pure $\mathrm{Zn}$ and $\mathrm{Zn}+3 \% \mathrm{wt} \mathrm{Sn}$ baths allow to obtain "multilayer" coatings with the "classical" intermetallic phases. Considering that a content of $3 \%$ of Sn is a factor of one higher than the Sn contents used in industrial applications, it implies that Sn addition do not modify the coating microstructure, but only fluidifies the bath. Focusing the intermetallic growth kinetics (Fig. 4), investigated Sn content implies an evident influence on the phase thickness-time curves, especially considering $\eta$ and $\zeta$ phases. Coatings obtained using pure $\mathrm{Zn}$ baths are characterized by a parabolic diffusion controlled growth (Fig. 4a). The Sn addition implies a different growth kinetic, with linear behaviour in which growth is interface controlled [2], Fig. 4b. Furthermore, Sn addition implies a decrease for the importance of $\zeta$ phase with respect to the other intermetallic phases (Fig. 4a and 4b).

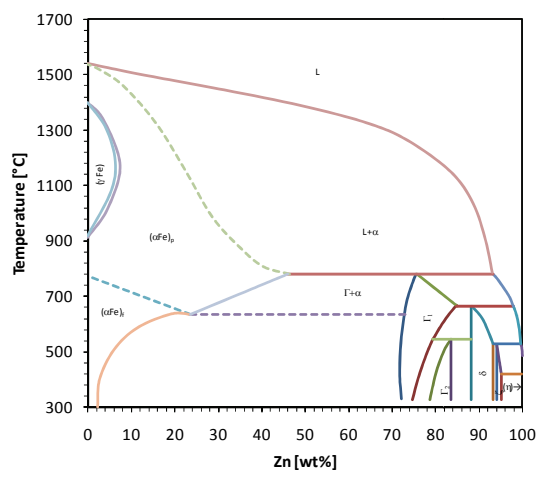

(a)

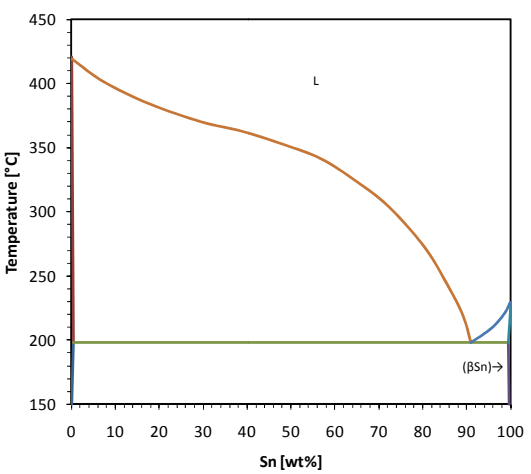

(b)

Figure 3: Phase diagrams. (a) Zn-Fe; (b) Zn-Sn.

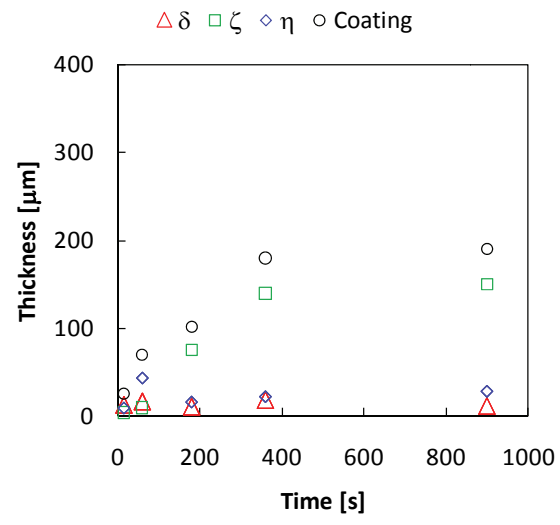

(a)

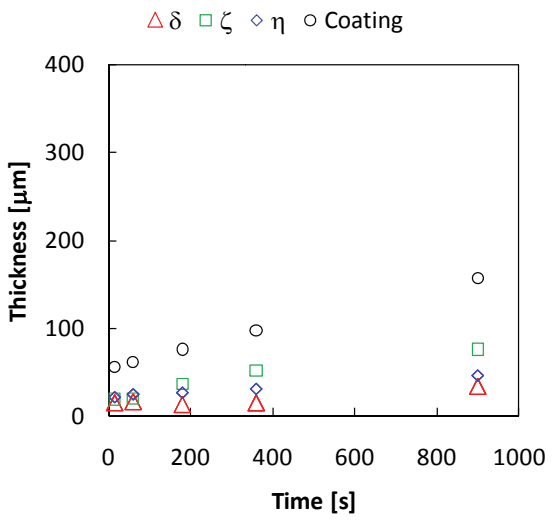

(b)

Figure 4: Coatings and intermetallic phases kinetics. (a) $\mathrm{Zn}$ bath; (b) $\mathrm{Zn}+3 \% \mathrm{wt} \mathrm{Sn}$ bath. 
Ti additions imply a strong modification of coatings microstructures. Considering binary Zn-Ti phase diagram (Fig. 5), many new intermetallic phases nucleate and grow with different chemical compositions, from $\mathrm{Zn}_{15} \mathrm{Ti}_{\mathrm{i}}$ to $\mathrm{ZnTi}$. Furthermore, solidification temperature strongly increases also for low Ti additions. Considering the investigated $\mathrm{Zn}+0.5$ \%wt Ti, no $\mathrm{Zn}_{\mathrm{x}} \mathrm{Ti}_{\mathrm{y}}$ intermetallic phases were observed [16], due to the low Ti content. Due to the Ti addition, and to the consequent $\mathrm{Ti}$ and $\mathrm{Zn}$ air oxidation, surface colours range from grey to violet.

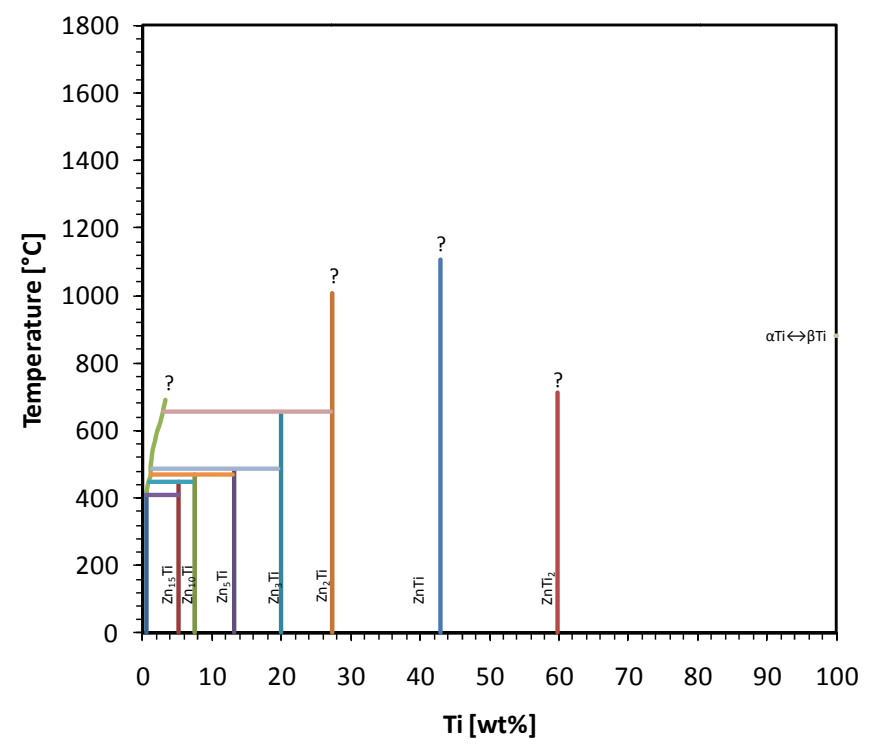

Figure 5: Zn-Ti phase diagram [15].

Coating microstructure is strongly affected by the Ti addition (Fig. 6). Near the iron substrate, a sort of $\Gamma$ phase is probably observed, but the thickness is too low to be described and quantified using a LOM. A compact "like $\delta$ " phase is present near iron-coating interface. The outer layer is characterized by a more complex microstructure. It is evident a compact phase (Fig. 6b, dark grey), with a sort of "chain" morphology, that is characterized by high Fe and Ti contents (about $7.6 \%$ and $3.5 \%$, respectively). Furthermore, a lamellar structure is observed mixed with a light grey phase. EDS chemical composition analysis show that the light grey phase is almost pure $\mathrm{Zn}$, and lamellar structure shows a not negligible $\mathrm{Ti}$ and Fe content (1.6\%wt and $0.6 \% \mathrm{wt}$, respectively).

Microhardness analysis shows an evident increase of Vickers values with the increase of the Fe and Ti contents (Tab. 2). Focusing dark grey phase, its microhardness is up to two times higher than the iron substrate.

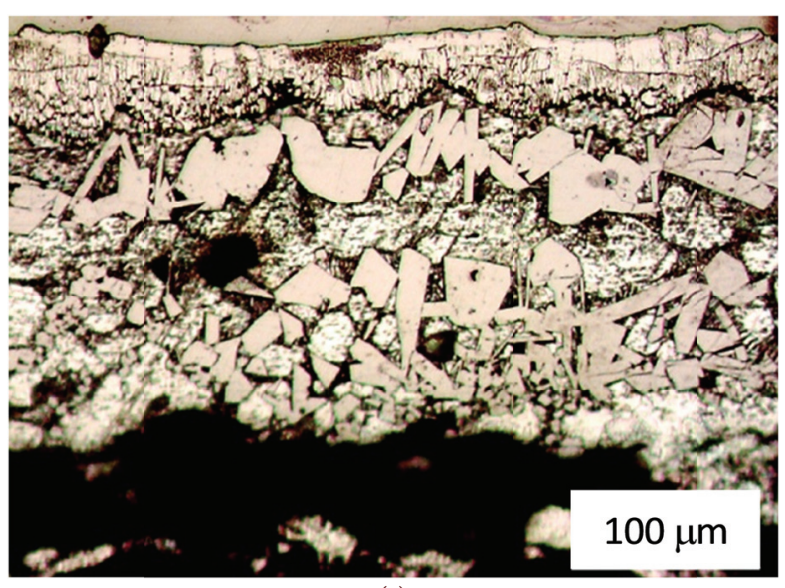

(a)

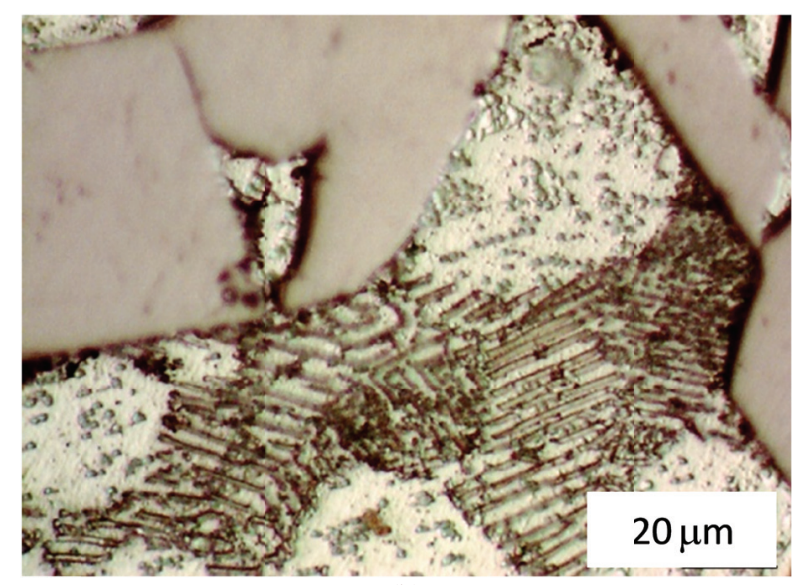

(b)

Figure 6: Zn-Ti coating microstructure (different magnifications): "like $\delta$ ", dark grey phase, light grey phase and lamellar structure. 

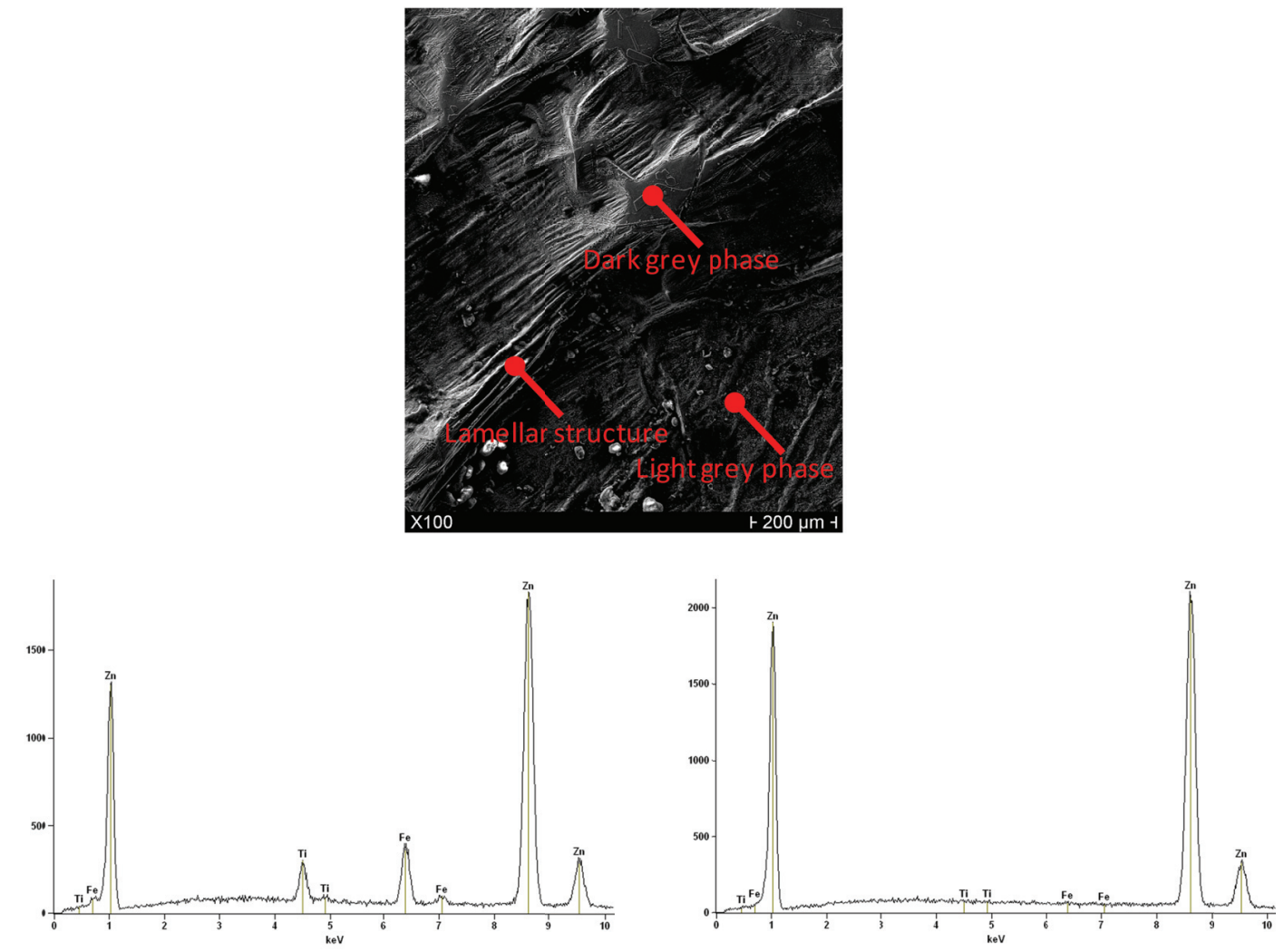

\begin{tabular}{ccc}
\hline Element & Weight $\%$ & Atom $\%$ \\
$\mathrm{Ti}$ & 3.48 & 4.63 \\
$\mathrm{Fe}$ & 7.62 & 8.70 \\
$\mathrm{Zn}$ & 88.90 & 86.68 \\
Total & 100.00 & 100.00 \\
\hline \multicolumn{3}{c}{ Dark grey phase }
\end{tabular}

\begin{tabular}{ccc}
\hline Element & Weight $\%$ & Atom \% \\
$\mathrm{Ti}$ & 0.17 & 0.23 \\
$\mathrm{Fe}$ & 0.17 & 0.20 \\
$\mathrm{Zn}$ & 99.66 & 99.57 \\
Total & 100.00 & 100.00 \\
\hline \multicolumn{3}{c}{ Light grey phase }
\end{tabular}

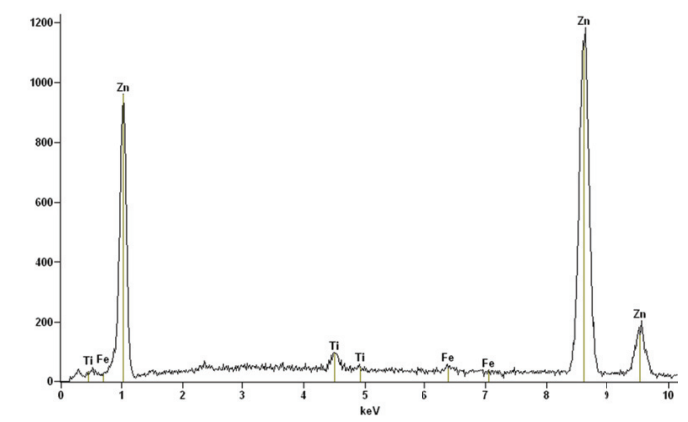

\begin{tabular}{ccc}
\hline Element & Weight \% & Atom \% \\
Ti & 1.62 & 2.20 \\
$\mathrm{Fe}$ & 0.60 & 0.70 \\
$\mathrm{Zn}$ & 97.78 & 97.10 \\
Total & 100.00 & 100.00 \\
\hline
\end{tabular}

Figure 7: $\mathrm{Zn}+0.5 \%$ wt Ti bath. SEM-EDS coating surface analysis 


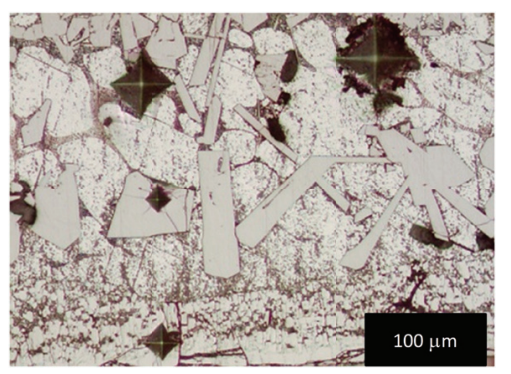

\begin{tabular}{cccc}
\hline $\begin{array}{c}\text { Like } \delta " \\
\text { phase }\end{array}$ & $\begin{array}{c}\text { Compact } \\
\text { dark grey } \\
\text { phase }\end{array}$ & $\begin{array}{c}\text { Lamellar } \\
\text { structure }\end{array}$ & $\begin{array}{c}\text { Light grey } \\
\text { phase }\end{array}$ \\
181 & 302 & 66 & 35 \\
\hline
\end{tabular}

Table 2: $\mathrm{Zn}+0.5 \%$ wt Ti bath. Intermetallic phases microhardness values $\left[\mathrm{HV}_{0.1}\right]$.

Ti strongly influences intermetallic phases growth kinetics (Fig. 8): after $180 \mathrm{~s}$, coating thickness with Ti is more than three times higher if compared to the coating obtained with a $\mathrm{Zn}$ or $\mathrm{Zn}+\mathrm{Sn}$ baths. "Mixed" zone (compact dark grey phase + lamellar structure + light grey phase) thickness is up to the $95 \%$ of the global coating thickness $(180 \mathrm{~s})$.

$\triangle \delta \quad \square$ Outer layer $\quad$ Coating

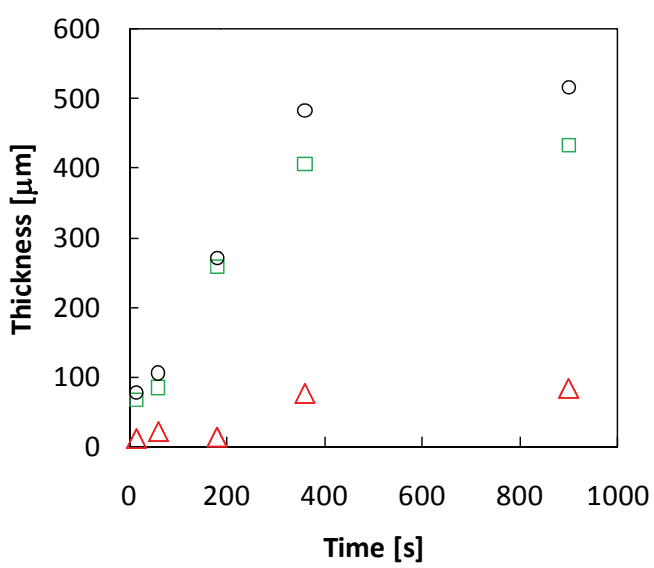

Figure 8: $\mathrm{Zn}-0.5 \%$ wt Ti bath. Dipping time influence on the coating and intermetallic phases thickness evolution.

\section{Coatings mechanical resistance and damage micromechanisms}

Bending moment - bending angle diagrams (Fig. 9) show the influence of coating chemical composition and microstructure on coatings mechanical resistance: the best behaviour corresponds to the coatings obtained using a $\mathrm{Zn}+$ $3 \%$ wt Sn bath: higher "YS" values are obtained and the coated plates are characterized by higher resistance values for all the investigated bending angles. The worst behaviour corresponds to the coating obtained using a $\mathrm{Zn}+0.5 \mathrm{Ti}$ bath, that is characterized by lowest "YS" values: furthermore, especially for lower dipping times, a decrease of the bending moment value with the bending angle is observed.

Damage analysis shows an evident influence of the coating chemical composition, microstructure and phase morphology (considering grains shapes, distribution and dimensions) (Fig. 10, 11 and 12).

Considering coatings obtained using a $\mathrm{Zn}$ bath (Fig. 10) and focusing the tensile specimen side, intermetallic phases distribution follows the "classical" morphology (Fig. 1). Lower dipping times imply radial cracks nucleation corresponding to the $\delta$ phase: these cracks could either be arrested corresponding $\delta$ - $\zeta$ interface or propagate in $\zeta$ phase. In this case the propagation could be arrested either in $\zeta$ phase or at $\zeta-\eta$ interface. Higher dipping times are characterized by an analogous damage morphology. Focusing the specimen compression side, only some thermal cracks were observed only corresponding to higher dipping times.

Considering cracks density as a quantitative damage parameter, the increase of the bending angle always implies an increase of the intermetallic phases damage, for all the investigated dipping times. It was not possible to identify an analytical relationship between dipping time and damage level, due to the strong influence of the dipping conditions to the intermetallic phases thickness. However, considering both Fig. 13a and $13 \mathrm{~b}$, it is evident that cracks arrest at $\delta$ - $\zeta$ interface is not a frequent phenomenon. 


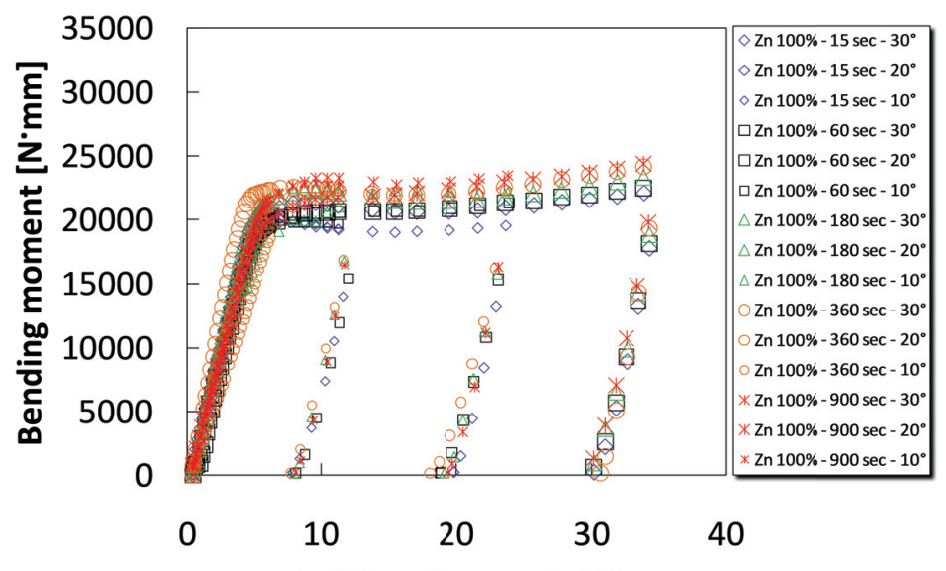

(a)

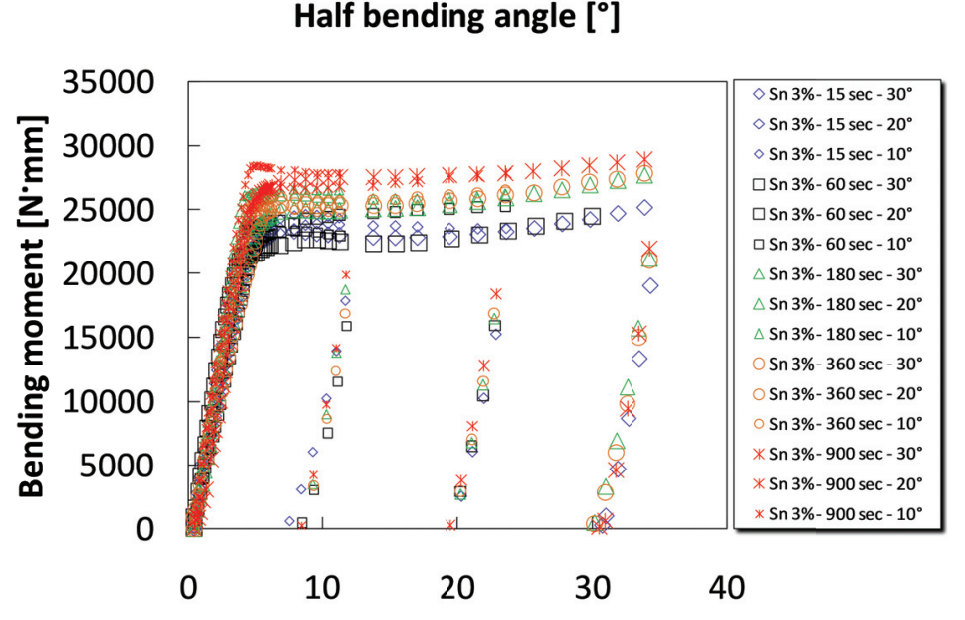

(b)

Half bending angle $\left[{ }^{\circ}\right]$

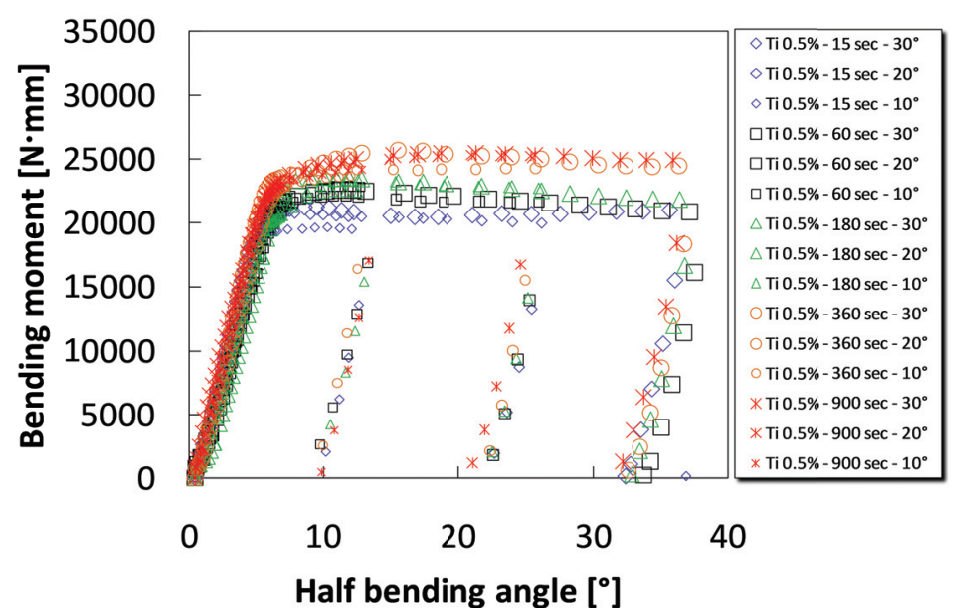

(c)

Figure 9: Dipping time influence on half angle-bending moment curve: a) Zn bath; b) Zn $+3 \%$ wt Sn bath; c) Zn $+0.5 \%$ wt Ti bath.

Considering coatings obtained using a $\mathrm{Zn}+3 \% \mathrm{wt} \mathrm{Sn}$ bath (Fig. 11) and focusing the tensile specimen side, intermetallic phases distribution always follows the "classical" morphology (Fig. 1). From a morphological point of view, damage distribution is not different if compared to the damage distribution formerly described (coating obtained using a $\mathrm{Zn}$ bath): lower dipping times imply radial cracks nucleation corresponding to the $\delta$ phase: these cracks could either be arrested corresponding $\delta$ - $\zeta$ interface or propagate in $\zeta$ phase. In this case the propagation could be arrested either in $\zeta$ phase or at 
$\zeta-\eta$ interface. Higher dipping times are characterized by an analogous damage morphology. Focusing the specimen compression side, no thermal cracks were observed, also corresponding to higher dipping times.

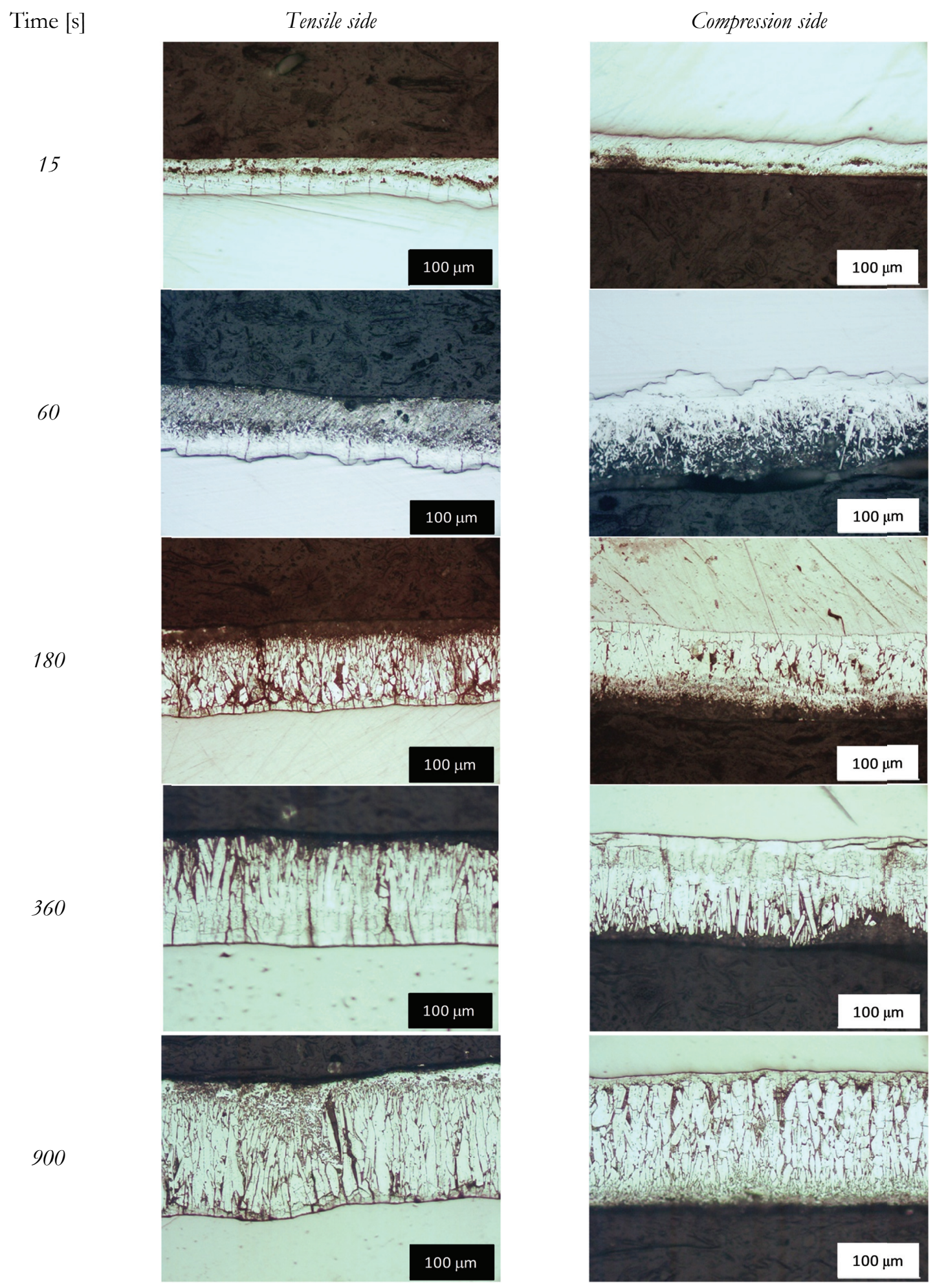

Figure 10: Coatings obtained using a $\mathrm{Zn}$ bath: LOM intermetallic phases damage morphology at $30^{\circ}$ half bending angle. 
Time $[\mathrm{s}]$

15

60

180

360

900
Tensile side

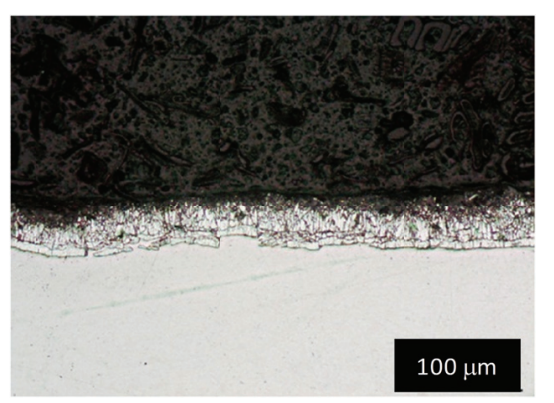

$100 \mu \mathrm{m}$
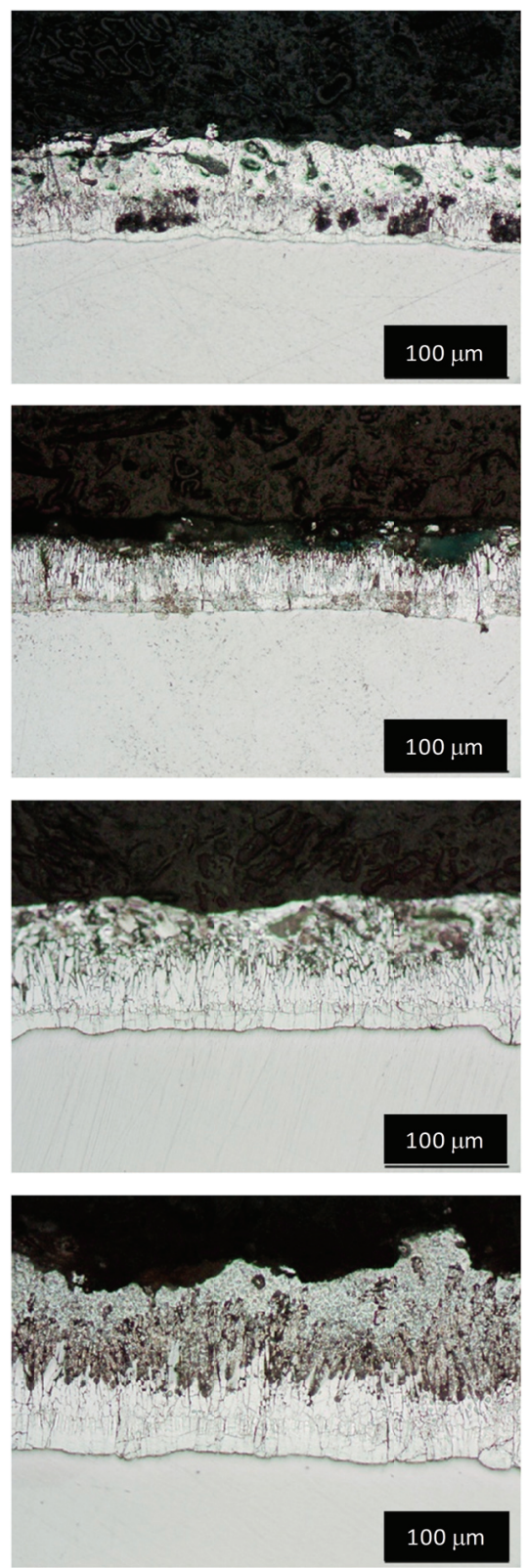

Compression side
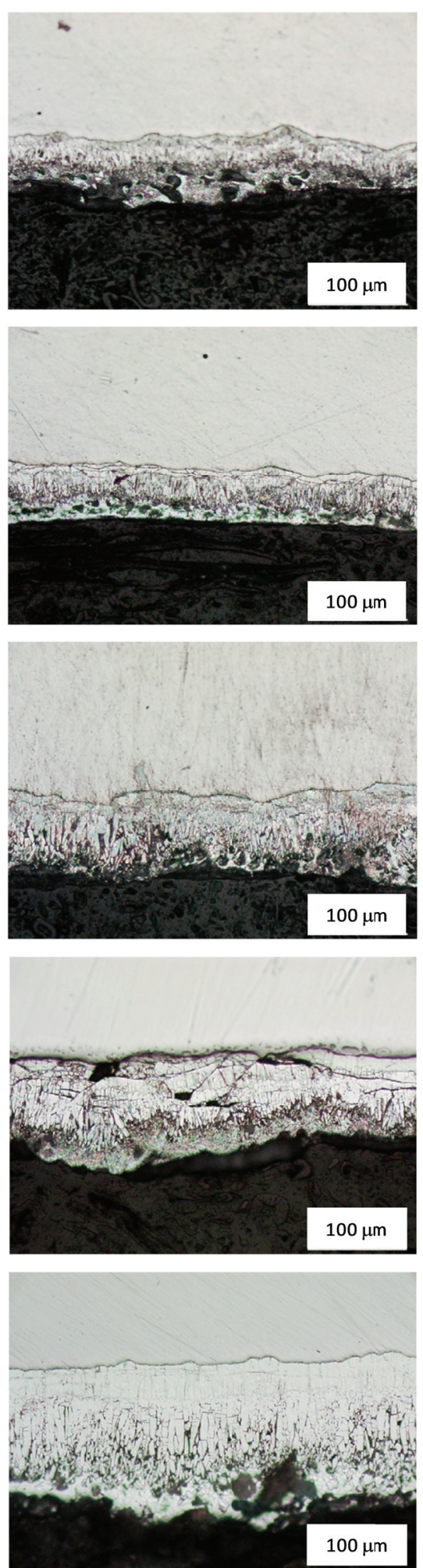

Figure 11: Coatings obtained using a $\mathrm{Zn}+3 \% \mathrm{wt}$ Sn bath: LOM intermetallic phases damage morphology at $30^{\circ}$ half bending angle. 
Time $[\mathrm{s}]$

15

60

180

360

900
Tensile side
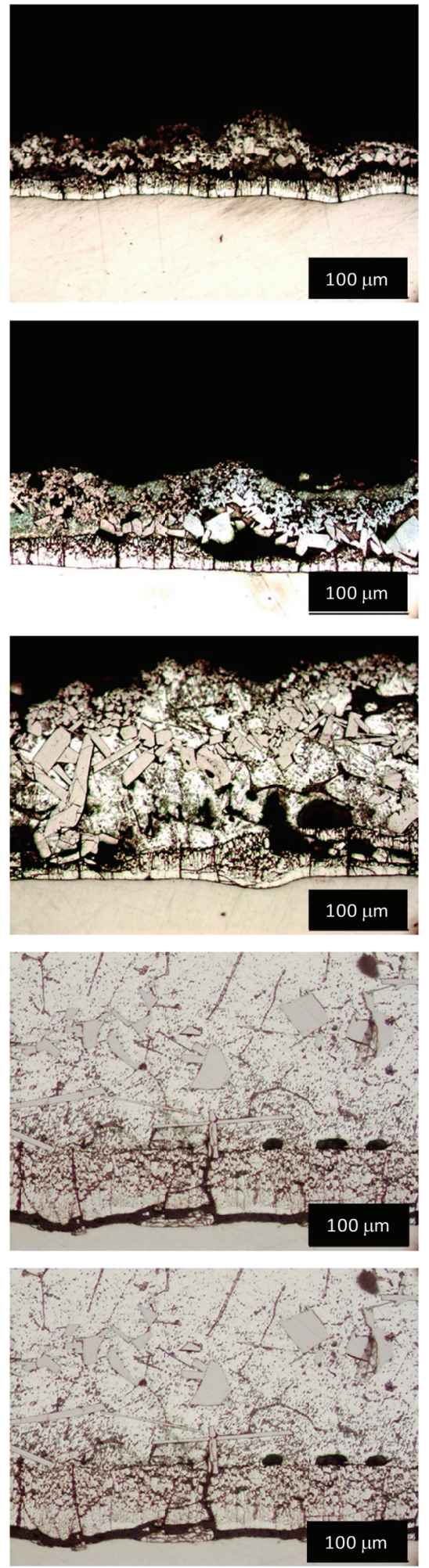

Compression side
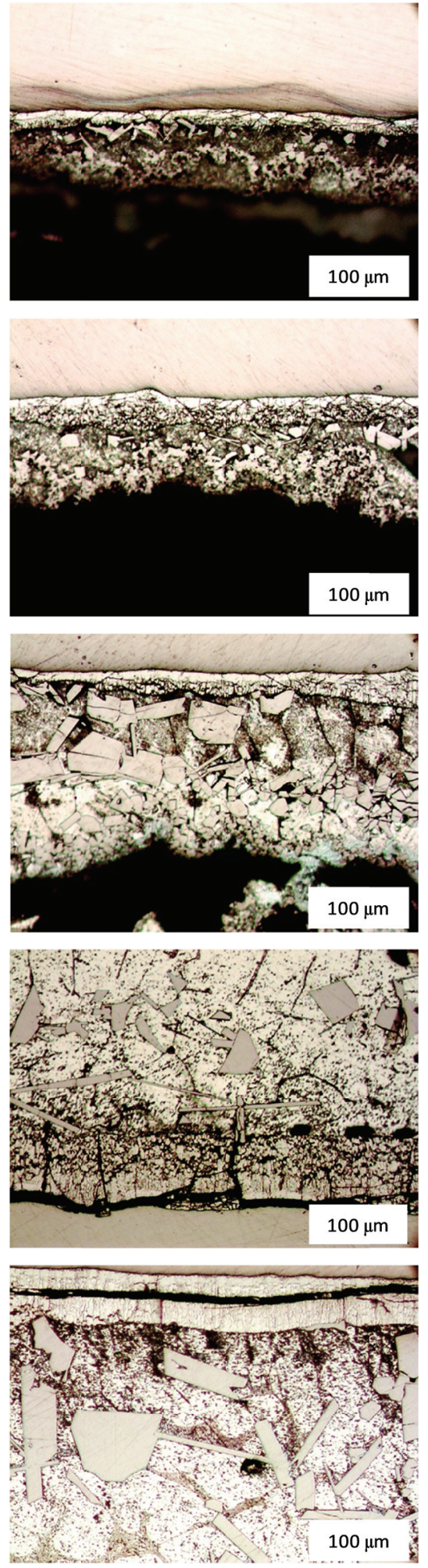

Figure 12: Coatings obtained using a $\mathrm{Zn}+0.5 \% \mathrm{wt}$ Ti bath:

LOM intermetallic phases damage morphology at $30^{\circ}$ half bending angle. 


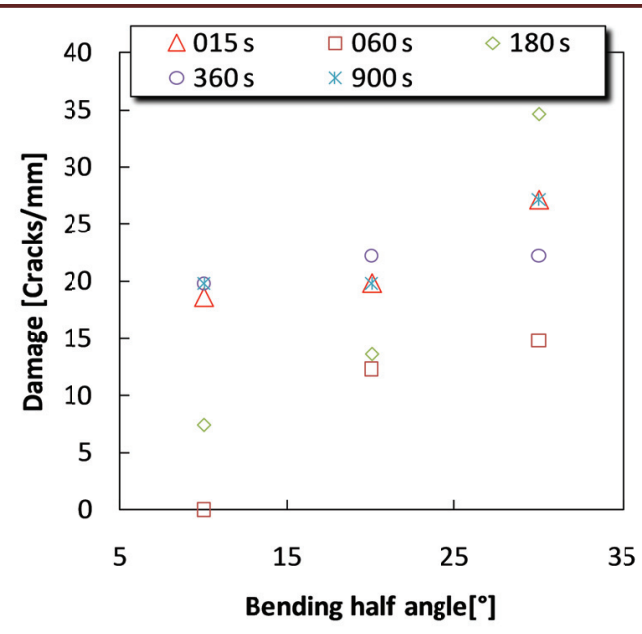

(a)

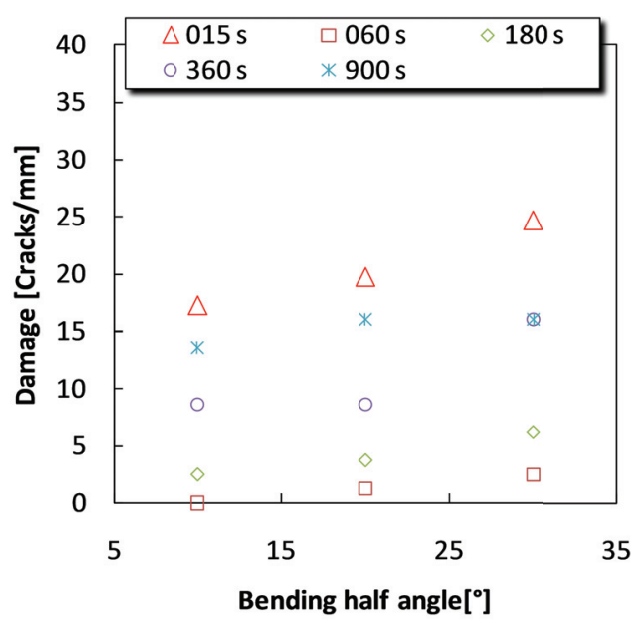

(b)

Figure 13: Coatings obtained using a $\mathrm{Zn}$ bath. Damage evolution in: (a) $\delta$ phase; (b) $\zeta$ phase.

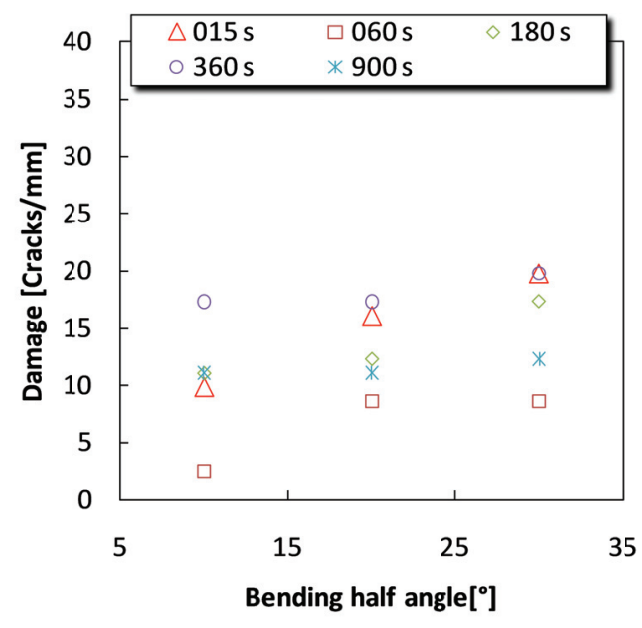

(a)

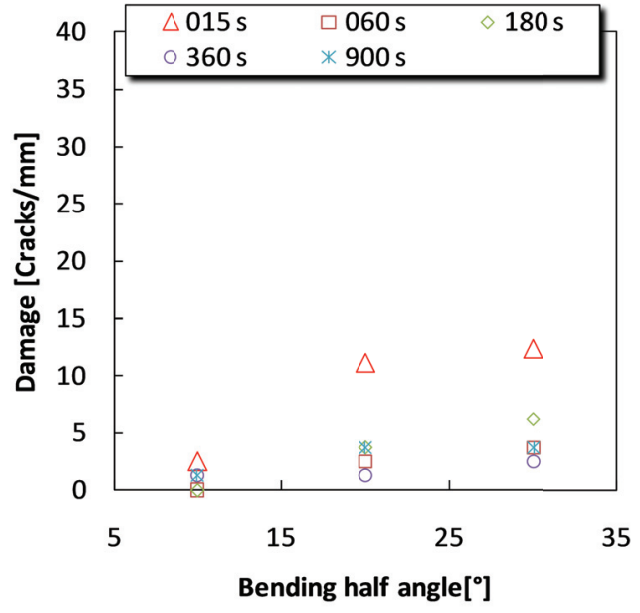

(b)

Figure 14: Coatings obtained using a $\mathrm{Zn}+3 \%$ wt $\mathrm{Sn}$ bath. Damage evolution in: (a) $\delta$ phase; (b) $\zeta$ phase.

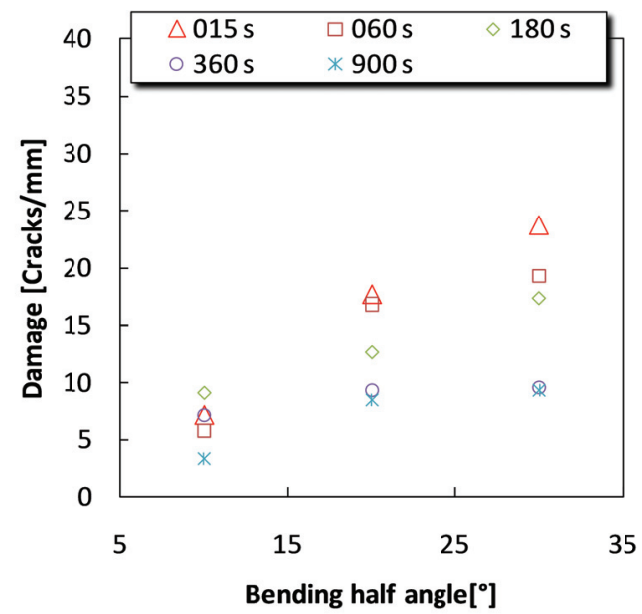

(a)

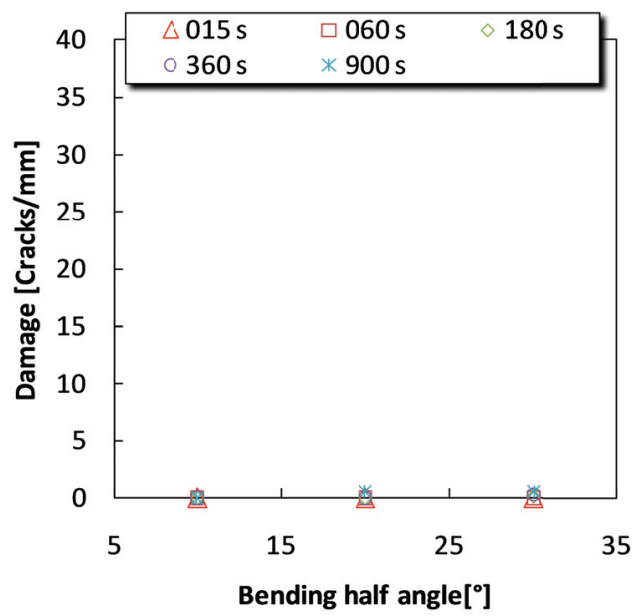

(b)

Figure 15: Coatings obtained using a $\mathrm{Zn}+0.5 \%$ wt Ti bath. Damage evolution in: (a) "like $\delta$ " phase; (b) outer layer (only radial cracks). 
Cracks density is lower if compared to coatings obtained using $\mathrm{Zn}$ baths, for all the investigated conditions, and cracks arrest at $\delta$ - $\zeta$ interface is a more frequent phenomenon (Fig. $14 \mathrm{a}$ and $14 \mathrm{~b}$ ).

Considering coatings obtained using a $\mathrm{Zn}+0.5 \%$ wt Ti bath (Fig. 12), phases distribution is really far from the "classical" distribution (Fig. 6). Focusing the tensile specimen side, three different damage morphologies were observed:

a) Radial cracks in "like $\delta$ " phase;

b) Longitudinal cracks at steel - "like $\delta$ " phase interface or in "like $\delta$ " phase grains

c) Light grey phase grains debonding, especially corresponding to higher bending angles.

Focusing the specimen compression side, both longitudinal cracks at steel - "like $\delta$ " phase interface and in "like $\delta$ " phase grains were observed. Furthermore, longitudinal cracks were also observed at "like $\delta$ " phase grains - outer layer interface. Cracks density values in "like $\delta$ " phase are analogous to the values observed in $\delta$ phase layers in coatings obtained using $\mathrm{Zn}$ and $\mathrm{Zn}+3 \% \mathrm{wt} \mathrm{Sn}$ baths (Fig. 15). The outer layer (dark grey phase + lamellar structure + light grey phase) does not show any radial or longitudinal cracks (Fig. 15b): this layer is characterized by the presence of microvoids, probably due to dark grey grains debonding (Fig. 12). This damaging mechanism is the responsible of the evident decrease of the coating resistance.

\section{CONCLUSIONS}

I $\mathrm{n}$ this work, the influence of dipping time and coatings chemical compositions on damaging micromechanisms was investigated considering different $\mathrm{Sn}$ and Ti contents by means of bending tests and LOM (Light Optical Microscope) observations.

On the basis of the experimental results, the following conclusions could be summarized:

$\checkmark \mathrm{Sn}$ addition to the $\mathrm{Zn}$ bath influences the intermetallic phases thickness evolution, probably due to Sn influence to the diffusion phenomena. Ti addition strongly modify coating microstructure. A new outer layer appears with different phases characterized by different $\mathrm{Fe}$ and Ti contents.

$\checkmark$ Coatings with Sn addition are characterized by an increase of the specimens mechanical resistance, for all the investigated conditions. On the contrary, Ti addition implies a strong decrease of the mechanical resistance.

$\checkmark$ Both $\mathrm{Zn}$ and $\mathrm{Zn}+\mathrm{Sn}$ coatings are characterized by the presence of cracks as main damaging micromechanism. Ti addition implies a new damaging micromechanims: microvoids are evident in the outer layer (dark grey phase + lamellar structure + light grey phase), probably due to dark grey grains debonding.

\section{REFERENCES}

[1] ASTM Handbook Corrosion, Hot dip coatings (1999) 13.

[2] A.R. Marder, Progress in Materials Science, 45 (2000) 191.

[3] Y. De Abreu, A. Da Silva, A. Ruiz, R. Réquiz, N. Angulo, R. Alanis, Surface and Coatings Technology, 120-121(1999) 682.

[4] T. Evangelos, G. Papadimitrou, Surface and Coatings Technology, 145 (2001) 176.

[5] G. Voct, J.B. Reumont, A. Iost, J. Foct, Surface and Coatings Technology, 139 (2001) 265.

[6] V. Di Cocco, F. Iacoviello, S. Natali, In: International Conference on Crack Paths, Parma, Italy (2006) 12.

[7] J.L. Duncan, S.-C. Ding, W.L. Jiang, International Journal of Mechanical Sciences 41 (1999) 249.

[8] J.L. Duncan, S.-C. Ding, W.L. Jiang, International Journal of Mechanical Sciences, 41 (1999) 261.

[9] S. Natali, V. Di Cocco, F. Iacoviello, La Metallurgia Italiana 7-8 (2004) 49.

[10] S. Natali, F. Iacoviello, V. Di Cocco, In: $32^{\circ}$ Convegno Nazionale AIM, Ferrara, Italy, (2008) 39.

[11] R. de Kort, W. Kets, H. van Kempen, Surface Science, (2001) 495.

[12] S.R. Kim, J.A. Narin, Engineering Fracture Mechanics, 65 (2000) 573.

[13] S.R. Kim, J.A. Narin, Engineering Fracture Mechanics, 65 (2000) 595.

[14] E.A. Sacco, N.B. Alvarez, J.D. Culcasi, C.I. Elsner, A.R. Sarli, Surface \& Coatings Technology, 168 (2003) 115.

[15] T.B. Massalski, Binary alloy phase diagrams, Vol. 2, ASM, Metals Park, Ohio 44073 (1986)

[16] A.R.B. Verma, W.J. van Ooij, Surface \& Coatings Technology, 89 (1997) 132. 